\title{
In-situ airborne observations of the microphysical properties of the Arctic tropospheric aerosol during late spring and summer
}

\author{
By ANN-CHRISTINE ENGVALL ${ }^{1 *}$, RADOVAN KREJCI ${ }^{1}$, JOHAN STRÖM ${ }^{2}$, ANDREAS \\ MINIKIN ${ }^{3}$, RENATE TREFFEISEN ${ }^{4}$, ANDREAS STOHL ${ }^{5}$ and ANDREAS HERBER ${ }^{6}$, \\ ${ }^{1}$ Department of Meteorology, Stockholm University, Stockholm, 106 91, Stockholm, Sweden; ${ }^{2}$ Department of Applied \\ Environmental Science - Atmospheric Science Unit, University of Stockholm, Stockholm, 106 91, Stockholm, Sweden; \\ ${ }^{3}$ Deutsches Zentrum für Luft- und Raumfahrt (DLR), Institut für Physik der Atmosphäre, Oberpfaffenhofen, 82234 \\ Weßling, Germany; ${ }^{4}$ Alfred-Wegener-Institut für Polar- und Meeresforschung, Telegrafenberg A43, 14473 Potsdam, \\ Germany; ${ }^{5}$ Norwegian Institute for Air Research, Instituttveien 18, 2027 Kjeller, Norway; ${ }^{6}$ Alfred-Wegener-Institut für \\ Polar- und Meeresforschung, Am Handelshafen 12, 27570 Bremerhaven, Germany
}

(Manuscript received 1 October 2007; in final form 22 February 2008)

\begin{abstract}
In-situ aerosol data collected in the Arctic troposphere during a three-week period in 2004 were analysed. The measurements took place during late spring, i.e., at the time of the year when the characteristics of the aerosol distribution change from being accumulation-mode dominated to being primarily of the Aitken-mode type, a process that previously has been observed in the boundary layer. To address the question whether this transition is also detectable in the free troposphere of an aircraft-measured data from the ASTAR 2004 campaign were analysed. In this study, we present vertically as well as temporally results from both ground-based and airborne measurements of the total number concentrations of particles larger than 10 and $260 \mathrm{~nm}$. Aircraft-measured size distributions of the aerosol ranging from 20 to $2200 \mathrm{~nm}$ have been evaluated with regard to conditions in the boundary layer as well as in the free troposphere. Furthermore an analysis of the volatile fraction of the aerosol population has been performed both for the integrated and size-distributed results. From these investigations we find that the transition takes place in the entire troposphere.
\end{abstract}

\section{Introduction}

The Arctic Study of Tropospheric Aerosol and Radiation (ASTAR) project is aimed at investigating the physico-chemical properties of the Arctic tropospheric aerosol by means of aircraft measurements. The goal of the program is to provide an observational data set for improving not only the assessment of the direct and indirect effects of aerosols on the Arctic radiative balance, but also the aerosol parameterisation in the regional climate model HIRHAM (Rinke et al., 1999; Treffeisen et al., 2005).

The ASTAR 2004 campaign was conducted from day 139 to 158 (May 18-June 7) in 2004. This timing was chosen to make the measurements span the transition period of the boundarylayer Arctic aerosol between spring (frequent Arctic hazes) and

\footnotetext{
*Corrisponding author.

e-mail: anki@misu.su.se

DOI: $10.1111 /$ j.1600-0889.2008.00348.x
}

summer conditions (clean). It is known from long-term groundbased observations during this transition that a systematic change of aerosol properties occurs, a process that regularly takes place in a relatively short period during late spring (Bodhaine et al., 1981; Bodhaine, 1989; Sirois and Barrie, 1999; Quinn et al., 2002; Ström et al., 2003).

Using continuous measurements encompassing a full year from the ground-based Zeppelin station near Ny-Ålesund on Svalbard, Ström et al. (2003) showed that the aerosol size undergoes a rapid $(\sim 10 \mathrm{~d})$ transition from being dominated by the accumulation mode to being primarily of the Aitken-mode variety. Corresponding transitions have been observed in the upper free troposphere (FT) in multiyear satellite-data records from the Stratospheric Aerosol Gas Experiment (SAGE) II and III (Treffeisen et al., 2006), which showed instances of rapid change of the aerosol optical properties from spring to summer.

Six years of ground-based measurements from the Zeppelin station were evaluated by Engvall et al. (2008) with special focus on processes that could control this annual transition of 
aerosol properties. Their conclusion was that the changes in source strength and transport are important for the annual variations of the aerosol properties, but these alone could not explain the observed rapid transition. Instead the increase of the solar radiance associated with the polar sunrise as well as a decreasing condensation sink (CS) with increasing cloudiness have been judged as having the potential to make new particles dominate the aerosol-distribution characteristics in summer-time.

The study by Engvall et al. (2007) was solely based on boundary-layer (BL) data, which raised the question whether the transition could be detected by aircraft in-situ observations above the BL. The previous study by Treffeisen et al. (2006), based on remote-sensing data averaged between $60^{\circ} \mathrm{N}$ and $80^{\circ} \mathrm{N}$, suggested that a transition also occurs at least in the upper FT.

In the present study, we address the question if a systematic change in aerosol microphysical properties also occurs in the FT, analogous the transition in the BL observed e.g. at the Zeppelin station. With the airborne measurements conducted during ASTAR 2004 it is feasible to cover a fairly large horisontal and vertical domain, but in general these observations are intermittent and of brief duration. Therefore, we will in this study combine the results from the airborne observations with the continuous long-term measurements at the Zeppelin station, this in order to if possible, examine the aerosol microphysical properties in a seasonal context. Consequently, we will here present the results of the airborne aerosol observations and link these to the transition.

\section{Instrumentation}

\subsection{Airborne instrumentation}

The scientific payload was flown on board a Dornier 228-200 aircraft (Polar 4) operated by the Alfred Wegener Institute (AWI), Germany, cf. Garbrecht et al. (2006). This twin-engine turboprop has an altitude ceiling of approximately $7.5 \mathrm{~km}$ and an endurance of $3.5 \mathrm{~h}$ with the ASTAR 2004 payload mounted. With a typical cruising speed of $75 \mathrm{~ms}^{-1}$, this implied an operational range of around $400 \mathrm{~km}$ from the campaign base at Longyearbyen airport, Svalbard. In total 63 flight hours during 19 missions were logged during the campaign.

For this investigation we used instrumentation from the Atmospheric Science Unit at the Department of Applied Environmental Science (ITM), Stockholm University and from the Institute of Atmospheric Physics at the German Aerospace Centre (DLR). This instrumentation provided information on the microphysical properties of the aerosol in a size range from 4 to $3500 \mathrm{~nm}$. A Condensation Particle Counter (CPC, TSI Inc. Model 3010) was used to obtain the total aerosol number density $\left(N_{10}\right)$ for particles larger than $10 \mathrm{~nm}$. The aerosol size distribution over the range between 20 and $2200 \mathrm{~nm}$ was derived from simultaneous measurements undertaken with a custom-made Differential
Mobility Particle Sizer (DMPS) and an Optical Particle Counter (OPC, Grimm GmbH model 7.309). The DMPS is based on a Hauke-type Differential Mobility Analyzer (DMA), cf. Knutson and Whitby (1975), coupled to a CPC TSI model 3010. The size range in which the DMPS was operated (20-250 nm) was divided into 15 bins, which resulted in a single size distribution being obtained every two and a half minutes. This device uses a closed-loop sheath air circulation system described by Jokinen and Mäkela, (1997). The aerosol sample flow was $2 \mathrm{~L} \mathrm{~min}^{-1}$, while the sheath airflow was $10 \mathrm{~L} \mathrm{~min}^{-1}$. This yields a rather broad transfer function, which improves counting statistics during periods of low aerosol concentrations. For illustration, when the total number concentration was $\sim 100 \mathrm{~cm}^{-3}$ in the size classes close to the mode of the size distribution, the uncertainties arising from the counting statistics are smaller than 5\% (one standard deviation).

The aerosol sample flow to the OPC was $2 \mathrm{~L} \mathrm{~min}^{-1}$. The OPC sized particles from 260 to $2200 \mathrm{~nm}$ in 12 bins at $1 \mathrm{~Hz}$ by inverting the scattered light into particle sizes. The total number concentration $\left(N_{260}\right)$ measured by this instrument covers part of the accumulation-mode particles. For a composite aerosol size distribution, OPC data were averaged and merged with DMPS data.

The uncertainty in the particle number concentration measured by the CPC and OPC instruments depends on the counting statistics or Poisson statistics. One standard deviation is given by the square root of the number of particles counted during a sampling period. The counting error for the CPC is smaller than $1 \%$ for number concentrations above $100 \mathrm{~cm}^{-3}$ and less than $3 \%$ for concentrations above $10 \mathrm{~cm}^{-3}$ (10 s average), respectively. For the OPC, a grand average distribution was calculated, where the counting error was less than $6 \%$ for sizes smaller than $1000 \mathrm{~nm}$.

Half of the sample flow downstream of the DMA was directed to a custom-built thermodenuder, where the aerosol was heated to $250{ }^{\circ} \mathrm{C}$. Particles, remaining after heating the sample air, were counted using a CPC TSI model 3010 . The temperature difference between the saturator and the condenser was increased for this $\mathrm{CPC}$, resulting in a cut-off at $6 \mathrm{~nm}$. The heating temperature of $250{ }^{\circ} \mathrm{C}$ was chosen to remove volatile and semi-volatile aerosols (e.g. sulphate, bisulphate and a large fraction of organics), which evaporate below $250{ }^{\circ} \mathrm{C}$. This volatility differential mobility particle size system (V-DMPS) was used to determine the volatility and derive the mixing state of the aerosol. During the campaign one flight (on day 145) was carried out with the thermodenuder switched off and the data collected were used to obtain size- and altitude-dependent corrections for losses in the thermodenuder system, thus allowing us to compare data from heated and unheated size distributions.

Particles with a diameter between 0.31 and $31 \mu \mathrm{m}$ were measured using a Forward Scattering Spectrometer Probe (FSSP300) provided by the DLR, which was mounted on the wing of the aircraft. This instrument classifies particles in 31 bins 
according to their forward-scattering properties. The FSSP-300 was used in this study for discrimination of in-cloud segments (see further below) based on the number concentration of particles larger than approximately $3 \mu \mathrm{m}$ (defined here as the total number of particles in the FSSP-300 channels 18-31). A detailed description of the FSSP-300 is given by (Baumgardner et al., 1992). The uncertainty in these measurements is below than $1 \%$ for particles smaller than $2800 \mathrm{~nm}$ and less than $10 \%$ for particles smaller than $15 \mu \mathrm{m}$. There are probably some additional uncertainties associated with the choice of the refractive index, which may vary depending on source region and composition of the aerosol.

Aerosol particles were also measured with the DLR condensation particle size analyser (CPSA). This is a custom-build instrument designed to measure the size distribution of aerosol particles in the range from 4 to $21 \mathrm{~nm}$ with a high temporal resolution (Stein et al., 2001). The instrument consists of four Butanol-operated condensation particle counter modules, where the minimum detectable particle sizes are controlled and monitored on the basis of the temperature difference between condenser and saturator. Particle-number concentrations are determined with a temporal resolution of $1 \mathrm{~s}$, and are estimated to be accurate within a 5\% error margin. During ASTAR 2004 two of the four CPSA modules were operated to determine the total number concentrations of particles larger than 4 and $13 \mathrm{~nm}$, respectively. The two other channels were set behind thermodenuders operating at 125 and $250{ }^{\circ} \mathrm{C}$, in order to determine the integrated relative fractions of volatile and non-volatile particles larger than $13 \mathrm{~nm}$.

The inlet used was designed and constructed at Stockholm University. It consists of forward-facing near-isokinetic and backward-facing inlets. The former was used for measurements of aerosol number density and size distribution in the OPC size range $260-2200 \mathrm{~nm}$. The rest of the instrumentation was connected to the backward-facing inlet. Although the design of the forward-facing inlet is based on purely theoretical considerations, the intercomparison measurements in the vicinity of Ny-Ålesund during aircraft fly-bys near the Zeppelin station demonstrated a very good agreement between 'airborne' and 'ground-based' size-distributions (not shown here), and thus we assume that no significant losses occur in the OPC measurement range. The backward-facing inlet consists of a $1 / 4^{\prime}$ pipe of stainless steel. An identical inlet has previously been used during measurements from faster observational platforms. The sampling efficiency was tested in-flight from the DLR Falcon 20 jet aircraft (cf. Schröder and Ström, 1997), where, with double the air speed, the inlet cut-off proved to be around $800 \mathrm{~nm}$.

2.1.1. Airborne data processing. The Micro Pulse Lidar (MPL) operated by the Japanese National Institute for Polar Research (NIPR) often shows cloud tops at an altitude of around $2000 \mathrm{~m}$ in the vicinity of Ny-Ålesund (Shiobara et al., 2003). In principle this feature could be used to demarcate the BL from the
FT. It must, however, be kept in mind that the experimental flights took place within a radius of $\sim 300 \mathrm{~km}$ from Longyearbyen and that the Arctic atmosphere may have several stable layers, not least in the form of the surface inversions which frequently are found over the pack ice (Tjernström et al., 2004).

Using the tropospheric thermal stratification with respect to the potential-temperature change with altitude, $\mathrm{d} \theta / \mathrm{d} z$, data from each flight were divided into BL and FT parts, with $\mathrm{d} \theta / \mathrm{d} z=0$ as the delimitation between these layers. This level was determined from visual inspection of the data from each flight. The BL height was found to vary from $\sim 750$ to $\sim 2250$ m during the campaign, cf. Table 1. It showed very little spatial variation during each flight, since these in general were made either over land or above the ocean. Based on this definition of the BL and FT we will investigate the temporal and spatial variations of the aerosolnumber concentrations and distributions.

Data from the FSSP-300 probe were analysed to determine the cloud and out-of-cloud segments of the flight paths. The cloud threshold was chosen semi-subjectively based on experience of how the instrument best distinguishes between background aerosol, haze and clouds. For the BL, this is set to 0.1 $\mathrm{cm}^{-3}$, and for the FT to $0.05 \mathrm{~cm}^{-3}$; in both cases for particles larger than $3 \mu \mathrm{m}$.

The use of two different thresholds originates from flight observations and data evaluation. It was found that the criterion for clouds in the FT could be based to a lower threshold, because clouds here tend to be less dense and furthermore the contribution of coarse sea-salt aerosol to the concentrations of particles larger than $3 \mu \mathrm{m}$ does not reach the FT to a large extent.

To avoid the influence of local emissions from Longyearbyen (the largest settlement on Svalbard of approximately 1700 inhabitants), data from flight segments within a sector from $78^{\circ}$ to $78.5^{\circ} \mathrm{N}$ and $15^{\circ}$ to $16^{\circ} \mathrm{E}$ were removed from the analysis. All concentration data shown in this study are normalized to standard temperature and pressure (STP): $273.15 \mathrm{~K}$ and $1013 \mathrm{hPa}$.

\subsection{Ground-based measurements at the Zeppelin station}

The Zeppelin station is located on Mount Zeppelin $474 \mathrm{~m}$ above sea level near the community of Ny-Ålesund, Svalbard. Given the elevated location, the effect of nearby particle sources such as Ny-Ålesund itself, sea spray, and resuspension of dust is strongly reduced. Effects from local atmospheric phenomena such as katabatic winds are also reduced.

The aerosol data from the Zeppelin station are provided by ITM at Stockholm University. The hourly averaged record includes the Zeppelin station total aerosol number density for particles larger than $10 \mathrm{~nm}$ obtained by a CPC TSI model 3010 as well as a size distribution that ranges from 20 to $630 \mathrm{~nm}$. The latter observations are carried out in the same manner as in the aircraft, with, however, a longer $(28 \mathrm{~cm})$ Differential Mobility Analyser (DMA) and slightly different flows being used at the Zeppelin station. The aerosol sample flow is $1 \mathrm{~L} \mathrm{~min}^{-1}$, while 
Table 1. Overview of flights during the ASTAR 2004 campaign. Some of the days two flights were performed, this is denoted a or $\mathrm{b}$ after the date corresponding the first or the second flight, respective, for that specific day, see column 1

\begin{tabular}{|c|c|c|c|c|c|c|c|}
\hline Date & Flight & Area & $\begin{array}{l}\text { Duration } \\
\text { (h) }\end{array}$ & $\begin{array}{l}\mathrm{BL} \\
(\mathrm{m})\end{array}$ & $\begin{array}{l}\text { Heating temperature of } \\
\text { sampled air }\left({ }^{\circ} \mathrm{C}\right)\end{array}$ & $\begin{array}{l}\text { Max altitude } \\
\text { (m) }\end{array}$ & $\begin{array}{l}\text { Flights when the } \\
\text { FV-DMPS system was running }(\mathrm{X})\end{array}$ \\
\hline 18 May 2004 a & $\# 1$ & Ny-Ålesund & 2.68 & 1250 & $125 / 250$ & 7002 & $\mathrm{X}$ \\
\hline 19 May 2004 a & $\# 2$ & Storfjorden & 2.47 & 2000 & 250 & 5579 & $\mathrm{X}$ \\
\hline 19 May 2004 b & $\# 3$ & Over land & 2.42 & 2000 & 250 & 5586 & $\mathrm{X}$ \\
\hline 21 May 2004 a & $\# 4$ & In vicinity of Ny-Ålesund & 2.39 & 750 & 250 & 7195 & $\mathrm{X}$ \\
\hline 22 May 2004 a & $\# 5$ & In vicinity of Ny-Ålesund & 2.56 & 2000 & 250 & 7127 & $\mathrm{X}$ \\
\hline 24 May 2004 a & $\# 6$ & Storfjorden & 2.51 & 2500 & - & 6829 & $X$ \\
\hline 26 May 2004 a & $\# 7$ & Down stream of Svalbard & 2.99 & 1900 & 250 & 3546 & $\mathrm{X}$ \\
\hline 26 May 2004 b & $\# 8$ & Down stream of Svalbard & 2.38 & 2250 & 250 & 6773 & $\mathrm{X}$ \\
\hline 27 May 2004 a & $\# 9$ & Ny-Ålesund & 1.92 & 1100 & 250 & 6796 & $\mathrm{X}$ \\
\hline 28 May 2004 a & $\# 10$ & Down stream of Svalbard & 2.25 & 1600 & $250 / 125 / 160 / 125 / 250$ & 6835 & $\mathrm{X}$ \\
\hline 28 May 2004 b & $\# 11$ & Down stream of Svalbard & 2.33 & 1500 & 250 & 1947 & $\mathrm{X}$ \\
\hline 29 May 2004 a & $\# 12$ & Down stream of Svalbard & 2.08 & 1250 & 250 & 3595 & $\mathrm{X}$ \\
\hline 31 May 2004 a & $\# 13$ & & 2.04 & 2500 & 250 & 5057 & - \\
\hline 1 June 2004 a & \#14 & Down stream of Svalbard & 2.50 & 1900 & 250 & & - \\
\hline 1 June 2004 b & $\# 15$ & Storfjorden & 2.19 & 2400 & 250 & 6766 & $\mathrm{X}$ \\
\hline 2 June 2004 a & \#16 & Storfjorden & 2.30 & 750 & & 3510 & - \\
\hline 3 June 2004 a & \#17 & Down stream of Svalbard & 2.43 & 1500 & 250 & 6782 & - \\
\hline 5 June 2004 a & $\# 18$ & Over land & 2.48 & 1500 & 250 & 3552 & $\mathrm{X}$ \\
\hline 7 June 2004 a & \#19 & In vicinity of Ny-Ålesund & 2.56 & 1250 & $125 / 250$ & 7110 & - \\
\hline
\end{tabular}

the sheath airflow is set to $5.5 \mathrm{~L} \mathrm{~min}^{-1}$. This yields a rather broad transfer function, but improves counting statistics during periods of low aerosol loading. When the total number concentration is $\sim 100 \mathrm{~cm}^{-3}$ in the size classes representing the main mode, the error is less than $5 \%$ (one standard deviation). The mobility distribution measured by the DMA (both aircraft and ground-based measurements) is inverted to yield a number distribution assuming a Fuchs charge distribution (Wiedensohler, 1988). Since the number concentration ranges over several orders of magnitude, the averages are calculated as geometric means.

In this study we use data in two size intervals $(251-630 \mathrm{~nm}$ and $316-630 \mathrm{~nm}$ ) from this system for comparisons with the airborne data.

\subsection{Transport modelling}

In order to investigate the origin and age of the air masses sampled during the campaign, atmospheric 'backward-transport' simulations were made using the Lagrangian particle dispersion model FLEXPART (Stohl and Thomson, 1999; Stohl et al., 2005)—see http://zardoz.nilu.no/ andreas/ASTAR/. The model was driven with $1^{\circ}$ resolution operational analysis data from the European Centre for Medium-range Weather Forecasts. The model calculates the trajectories of what is known as tracer particles using the mean winds interpolated from the analysis fields plus random motion representing turbulence and moist convection. Removal processes were not considered in the simulations.
Simulations were initiated at points along the flight tracks characterised by the aircraft changing its position by more than $0.2^{\circ}$, or when it below $300 \mathrm{~m}$ changed its altitude by $50 \mathrm{~m}$, below $1000 \mathrm{~m} \times 150 \mathrm{~m}$, below $3000 \mathrm{~m} \times 200 \mathrm{~m}$, and above $3000 \mathrm{~m} \times$ $400 \mathrm{~m}$.

The backward-mode output of FLEXPART is a potential emission sensitivity (PES) function. The word 'potential' indicates that this sensitivity is based on transport alone, neglecting removal processes that would reduce the sensitivity. The value of the PES function (in units of $\mathrm{s} \mathrm{kg}^{-1}$ ) in a particular grid cell is proportional to the particle residence time in that cell. It is a measure of the simulated mixing ratio at the receptor that a source of unit strength $\left(1 \mathrm{~kg} \mathrm{~s}^{-1}\right)$ in this particular grid cell would produce. We inspected column-integrated PES values as well as the PES in a so-called footprint layer extending from the surface to a height of $100 \mathrm{~m}$. The latter shows where an air mass was probably in contact with the surface and thus could have taken up emissions.

Folding (i.e. multiplying) the PES footprints with the emission flux densities of the species carbon monoxide $(\mathrm{CO})$ in units of $\mathrm{kg} \mathrm{m}^{-2} \mathrm{~s}^{-1}$ from an emission inventory (we used the EDGAR 3.2 fast-track inventory for the year 2000; see Olivier and Berdowski, 2001) yields potential source contribution (PSC) maps, which show the geographical distribution of contributing sources. Spatial integration finally gives the simulated mixing ratio at the receptor. Since the timing of the emission input is also known from the backward simulations, the mixing ratio can be split into PSCs of different age with a 
1-day resolution. For display purposes, we calculated the mean age of the CO PSC. Since the FLEXPART simulations extended back only $20 \mathrm{~d}$, older contributions are ignored in this calculation.

\section{Results}

Here we will present airborne aerosol data and discuss their spatial and temporal variations. After removing in-cloud data (cf. Section 2) and influences from Longyearbyen, the final data set comprises $42 \mathrm{~h}$ of measurements covering the Arctic tropospheric column. Furthermore the aerosol data in terms of total numbers and size-distributions will be compared to the nonvolatile fraction of the aerosol population.

In Table 1 we present a summary for each flight including the maximum flight level, the geographical area covered by the flight, the BL height, the temperature of the heater, etc.

\subsection{Representativeness of the airborne and ground-based measurements}

To evaluate how well aircraft data from all flights are capturing the trend based on the continuous BL observations at the Zeppelin station, the temporal evolution of $N_{260}$ from the aircraft is compared with that of hourly-averaged DMPS data from the Zeppelin station. The number densities of (251-630 nm)- and (316-630 nm)-particles as well as the airborne values of $N_{260}$ are shown in Fig. 1a. Note that the aircraft data have been obtained using an OPC and the Zeppelin data from the DMPS system. The $N_{10}$ values observed from the aircraft are graphed together with hourly total particle concentrations (particles larger than 10 $\mathrm{nm}$ ) from the Zeppelin station, Fig. 1b. Although smaller particles show a larger variation since they in general have shorter lifetimes than the larger particles, the airborne BL data remain within the variability limits of the ground-based continuous observations.
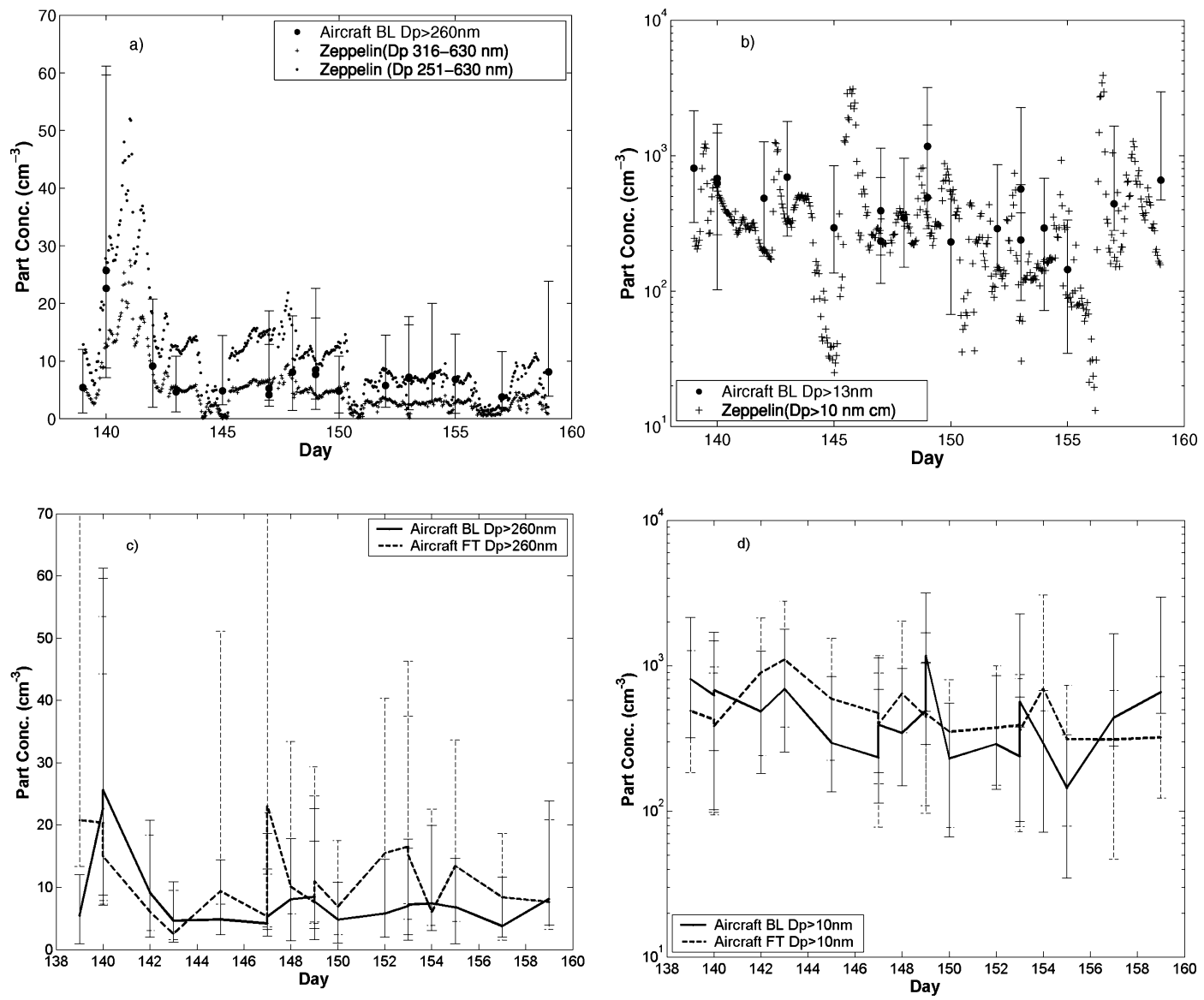

Fig. 1. Time series of the measured data from the aircraft and the Zeppelin station from day 139 to 1602004 (corrected for STP). (a) Temporal variations of the hourly particle concentrations from the DMPS at the Zeppelin station (grey circles: $251-630 \mathrm{~nm}$ and grey plus: 316-630 nm), and, in black, the daily averaged (GM and GSTD) BL particle concentrations from the OPC on the aircraft. (b) Hourly data of $N_{10}$ (larger than $10 \mathrm{~nm}$ ) particle concentrations from the Zeppelin station compared to the total number concentrations (GM and GSTD) of $N_{10}$ particles measured from the aircraft in the BL. (c) The black line represents BL OPC data from the aircraft [corresponding the black filled circles in (a)]. The dashed line pertains to the same type of data when the aircraft operated in the FT. (d) The black line represents BL CPC data, that is, $N_{10}$, from the aircraft [corresponding to the black filled circles in (b)] and the dashed line represents the same type of data from when the aircraft operated in the FT. 
Even though the instrumentation, the observation and the sampling times differ between aircraft and ground measurements, the trends of the ground-based data are captured by the airborne BL observations. This nicely illustrates how well the long-term measurements from the Zeppelin station represent Svalbard and the surrounding Arctic region. Despite the intermittent airborne observations (on average three flights in $4 \mathrm{~d}$ ), the temporal evolution of the aerosol properties is captured.

In Figs. 1c and d the airborne data from the BL are compared to those from the FT. Except during three flights in the beginning of the campaign the airborne $N_{260}$ concentrations have a larger geometric-mean concentration in the FT compared to the conditions in the BL. Analogously the $N_{10}$ particle concentrations in the FT have a geometric-mean concentration larger than that in the BL, except during a few flights.

\subsection{The Arctic aerosol transition from spring to summer}

The emissions giving rise to Arctic haze are most intensive during the period from March to May (Quinn et al., 2007). Figure 2a shows the time evolution from spring to summer of the condensable sink (CS) based on measurements of the accumulation-mode particles (which dominate the size distribution during the haze period). A decreasing trend from April to June, which accompanies the annual variation of the accumulation-mode particles (Ström et al., 2003), is in clear evidence. ASTAR 2004 took place during the later part of May, i.e. after the period characterised by the most intensive anthropogenic inputs to the Arctic atmosphere. (Actually the campaign encountered even less contaminated conditions than usual at this time of the year.) Despite these reservations the data may be regarded as representative of a polluted spring and a clean summer. But, as can been seen from Fig. 2a, the summer of 2004 was affected by a mid-June pollution event, a phenomenon that can occur in summer, although less severely than during the Haze period.
To systematically investigate the changes of the aerosol characteristics, the campaign was divided into three periods using the criterion for when the transition took place in the BL proposed by Engvall et al. (2008). This criterion is based on the equilibrium concentrations for which the production of $\mathrm{H}_{2} \mathrm{SO}_{4}$ balances the sink of this vapour due to the pre-existing aerosol surface area, cf. Fig. 2b. This graph shows the ratio between the number of data points exceeding a prescribed threshold of $\mathrm{H}_{2} \mathrm{SO}_{4}$ equilibrium concentration, divided by the total number of data points within one week time window. There is a clear shift from day 142 where the ratio increases and stays over 0.3 , which then is defined as the transition between spring and summer. We refer to the above-mentioned study for more details concerning the derivation of this quantity. Here we will simply adopt this method for organising our data in three different periods. Application of this criterion to the data from the entire campaign (cf. Engvall et al., 2008) ultimately yielded that the transition took place between day 142 and 150 .

On the basis on these results and the flight-days we divide the campaign into three periods; the pre-transition period (day 139-145, six flights), the transition period (day 147151 , seven flights), and the summer period (day 152-158, six flights).

\subsection{Vertical characteristics of the number concentrations and size distributions}

For a general picture of the Arctic aerosol and its vertical variation in the troposphere during the campaign we calculate the geometric mean (GM) and standard deviation (GSTD) of the $N_{10}$ and $N_{260}$ particles number densities. For each experimental period the concentrations are averaged over 100 - $\mathrm{m}$ altitude bins through the entire tropospheric column from 0 to $7000 \mathrm{~m}$, cf. Figs. 3a-f. The BL and the FT statistics are presented in Table 2.
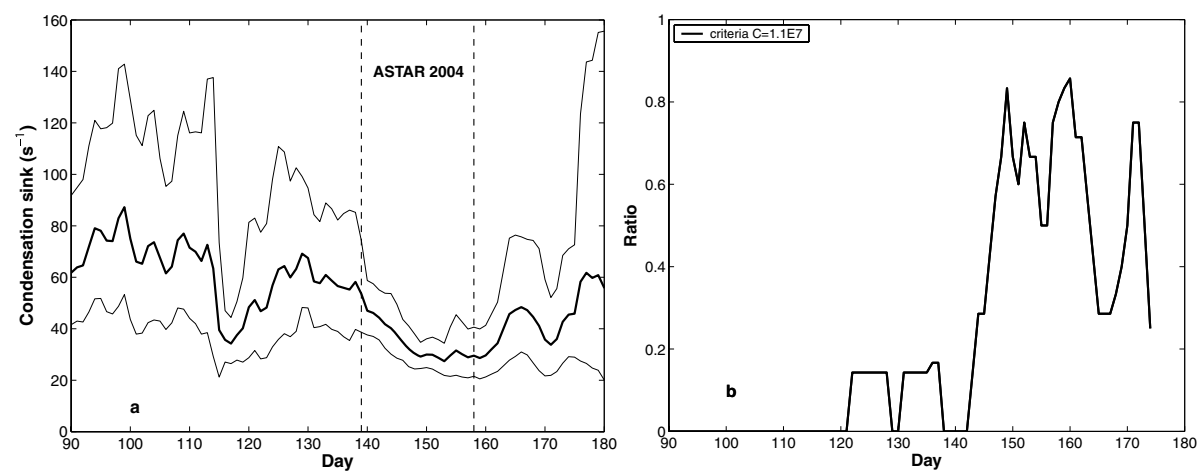

Fig. 2. (a) The weekly moving average (heavy solid line) and \pm 1 standard deviation (weak solid lines) of the condensation sink (CS) based on particle measurements at the Zeppelin station for the period April through June 2004. The period for when the ASTAR 2004 campaign is marked between the two vertical dashed lines. (b) The ratio between the number of data points exceeding a prescribed threshold of $\mathrm{H}_{2} \mathrm{SO}_{4}$ equilibrium concentration, divided by the total number of data points within one week time window. 

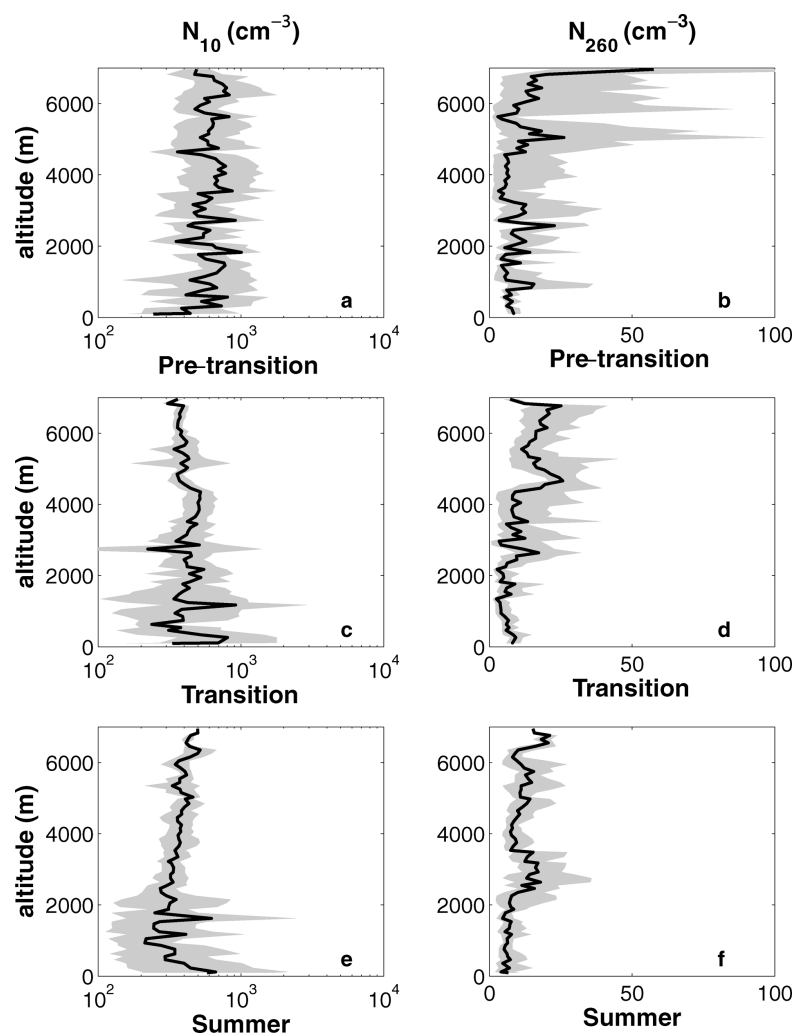

Fig. 3. Vertical profiles of the geometric mean and geometric standard deviation (shaded area) of the $N_{10}$ - and $N_{260}$-particle concentrations (corrected for STP) for the pre-transition (a and b), transition (c and d) and summer ( $\mathrm{d}$ and $\mathrm{f}$ ) periods.

The GM and GSTD of the $N_{10}$ concentrations do not show any noticeable differences in absolute numbers between the BL and FT during the three periods, cf. Table 2. It should instead be underlined that during the campaign a clear shift took place in the variability characteristics of both the FT and BL data. In the FT during the pre-transition phase it is between 100 and $1500 \mathrm{~cm}^{-3}$ and decreases to $200-300 \mathrm{~cm}^{-3}$ during the transition and summer periods. Similar estimates for the BL yielded a variation between
100 and $1000 \mathrm{~cm}^{-3}$ during the pre-transition period and 20$4000 \mathrm{~cm}^{-3}$ during the transition and summer phases. During the latter periods enhanced particle concentrations (up to $\sim 7300 \mathrm{~cm}^{-3}$ ) appear in layers at diverse altitudes, which vary between each flight. In contrast, the pre-transition period shows a variability that is more-or-less equally distributed over all altitudes within the BL as well as the FT, and this holds true for each flight. The minimum as well as the maximum particle concentrations during the entire campaign were found in the summer period (BL: 19 and $7300 \mathrm{~cm}^{-3}$; FT: 113 and $6500 \mathrm{~cm}^{-3}$ ).

Investigating the behaviour of the $N_{260}$ particle concentrations, cf. Figs. 3b, d and e, these appear to have similar GM and GSTD characteristics in the BL with during all three periods, cf. Table 2. The FT, on the other hand, shows a larger variability with a weakly decreasing trend towards summer.

Beside the variation in the absolute number concentration of $N_{260}$ we note changes in the vertical structure of the concentrations during the three periods. Enhanced particle concentrations of up to $\sim 180 \mathrm{~cm}^{-3}$ were found in the FT during the pre-transition period. The summer period is characterised by layered structures with high particle concentrations of up to $40 \mathrm{~cm}^{-3}$ at altitudes between 2000 and $3500 \mathrm{~m}$ as well as from 5000 to $6000 \mathrm{~m}$. This feature was found during all flights. Between these layers the variation is smaller, viz. $5-10 \mathrm{~cm}^{-3}$. We note that these layers with enhanced concentrations do not show the large variations of the concentrations found in the pre-transition period; the summer variability is between 5 and $40 \mathrm{~cm}^{-3}$ compared to the pre-transition variability of up to 20 $120 \mathrm{~cm}^{-3}$.

Summarising these results one finds changes in the structure of the variations of the aerosol number concentrations between the three constituent periods, cf. Figs. 3a-f. During the pre-transition phase, there is generally no specific difference in $N_{10}$ variability between the BL and the FT compared to the subsequent transition and summer periods, which show an enhanced variability in the BL compared to the FT. $N_{260}$ has a low variability in the BL for all periods, but during the pre-transition phase a large variability is found in the FT, which decreases towards summer. The

Table 2. Statistics of the particle number concentrations $\left(\mathrm{cm}^{-3}\right)$ for the boundary layer (BL) and the free troposphere (FT) for the three periods. GM: geometric mean; GSTD: geometric standard deviation; $N_{260}=$ particles $>260 \mathrm{~nm}, N_{10}=$ particles $>10 \mathrm{~nm}$ and $N_{\text {DMPS }}$ : the integrated average size distribution

\begin{tabular}{|c|c|c|c|c|c|c|}
\hline & \multicolumn{3}{|c|}{$\mathrm{BL}$} & \multicolumn{3}{|c|}{ FT } \\
\hline & $N_{260} \mathrm{GM}(\mathrm{GSTD})$ & $N_{10}$ & $N_{\text {DMPS }}$ & $N_{260}$ & $N_{10}$ & $N_{\text {DMPS }}$ \\
\hline Pre-transition & $6(3-12)$ & $\begin{array}{c}529 \\
(273-1024)\end{array}$ & 381 & $10(5-21)$ & $\begin{array}{c}587 \\
(341-1011)\end{array}$ & 326 \\
\hline Transition & $6(3-12)$ & $\begin{array}{c}436 \\
(176-1076)\end{array}$ & 294 & $12(6-24)$ & $\begin{array}{c}443 \\
(273-718)\end{array}$ & 292 \\
\hline Summer & $6(3-11)$ & $\begin{array}{c}338 \\
(132-861)\end{array}$ & 179 & $10(5-20)$ & $\begin{array}{c}398 \\
(194-817)\end{array}$ & 249 \\
\hline
\end{tabular}



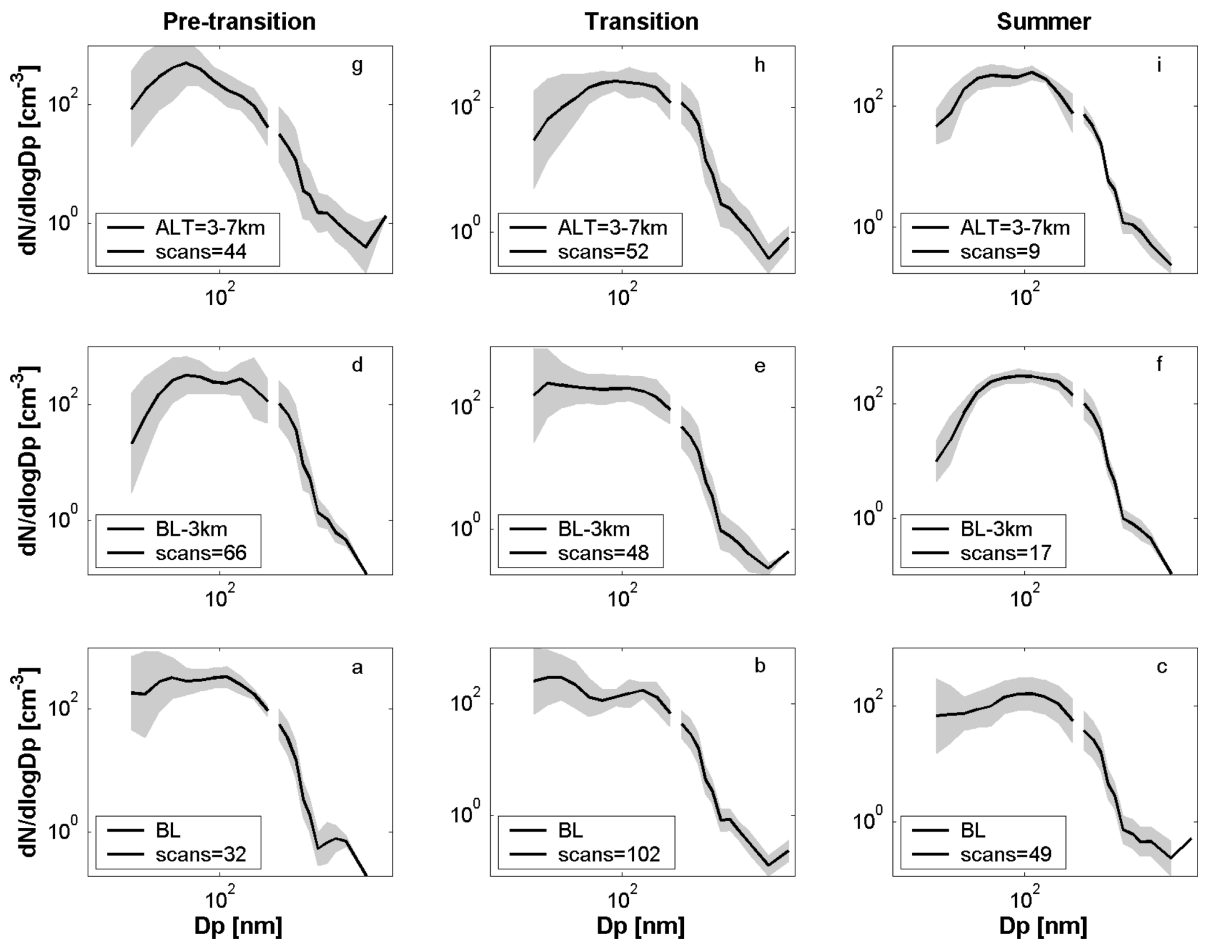

Fig. 4. Geometric means and standard deviations of the size distributions from the two independent DMPS and OPC systems (data corrected for STP). The DMPS range is from 20 to $250 \mathrm{~nm}$ and that of the OPC is from 260 to $2200 \mathrm{~nm}$. Panels (a-c) show data in the BL, panels (d-f) data between the top of the BL to $3 \mathrm{~km}$, and panels (g-i) show data between 3 and $7 \mathrm{~km}$. Panels (a, d, g), (b, e, h) and (c, f, i) show pre-transition, transition and summer results, respectively.

$N_{260}$ GM furthermore shows an increase with altitude in the summer period.

To obtain more information about the aerosol characteristics we investigate the size distributions of the aerosols determined by the airborne DMPS and OPC systems, cf. Figs. 4a-i. Since these have a coarse temporal resolution (150 s) due to the scanning time for each particle size, the amount of data from this system is more limited than that from the CPCs and the OPC operated at a frequency of $1 \mathrm{~Hz}$. During the pre-transition period, all flights were performed with the DMPS system running. During the transition and summer periods 6 out of 7 and 2 out of 6 flights, respectively, had the DMPS system running. Based on Fig. 1 showing that the airborne data are reliable in a long-term context, we conclude that even though the flights with an operational DMPS system are fewer in the summer period, the amount of data obtained is still sufficient for this approach. As seen in Figs. $4 \mathrm{a}-\mathrm{i}$, the merged results from the DMPS (20-250 nm) and the OPC (260-2200 nm) are distinguished by a gap in the graph. The OPC-derived distributions are averages over $150 \mathrm{~s}$ for consistency with the scan time of the DMPS system.

The size-distribution data are presented for three vertical layers, one of which is the BL, Figs. $4 \mathrm{a}-\mathrm{c}$. The FT is divided into two layers: FT1 from the top of the BL to $3 \mathrm{~km}$ (Figs. 4d-f) and FT2 from 3 to $7 \mathrm{~km}$ (Figs. $4 \mathrm{~g}-\mathrm{i}$ ).
Note that the upper part of the summer-period FT results is based on 9 scans compared to 30-100 for the other profiles. However, this result appears to be consistent with the vertical profiles, cf. Fig. $3 \mathrm{c}$ representing averaged data from six flights not least in view of Figs. 1a-d showing the reliability of the airborne data. Here it is well worth emphasizing that the airborne measurements from the boundary layer captured the temporal evolution of the aerosol properties as measured at the Zeppelin station, despite the intermittent character of the aerial surveys (on average 3 flights in 4 days).

For the FT as a whole, the integrated mean number densities of the size distributions ( $N_{\text {DMPS }}$ ) during the three periods do not show any dramatic changes, cf. Table 2 . The values of $N_{10}$ together with these numbers suggest that about one third to one half of the particles are smaller than $20 \mathrm{~nm}$.

By examining all size distributions within each period (not shown here) it is recognised that around $50 \%$ of all pre-transition size-distributions in the FT represent situations when Aitkenmode $(\sim 50 \mathrm{~nm})$ particles coexist with low concentrations of accumulation-mode particles $(100-500 \mathrm{~nm})$. This is a characteristic feature of an air mass dominated by condensation and coagulation of small and recently formed particles in the absence of larger accumulation-mode particles potentially serving as a sink and hereby inhibiting growth. 
From Figs. $4 \mathrm{~d}-\mathrm{i}$ it is recognised that during the pre-transition and transition phases the smallest particles show a larger variability than they do in summer. This indicates that during these periods recent particle formation has influenced the distribution. The summer period, on the other hand, shows an almost monomodal size distribution $(\sim 100 \mathrm{~nm})$, which indicates an aged air mass.

During the pre-transition and transition periods, the sizedistribution in the BL appears to have a larger variability for the small-size modes (20-50 nm) compared to those between 50 and $2200 \mathrm{~nm}$. The summer period, on the other hand, shows a larger variability for particles between 20 and $30 \mathrm{~nm}$ compared to those between 30 and $250 \mathrm{~nm}$. The summer size-distribution shows an overall larger BL variability of particle sizes around $100 \mathrm{~nm}$ compared to the two preceding periods. During the entire campaign the distributions in the BL manifest what is known as 'open' characteristics, i.e., there is a nucleation mode beyond the smallest size. The transition period also shows a bimodal distribution (30 and $200 \mathrm{~nm}$ ), an indication that cloud-related processes have affected the aerosol.

In the BL the smaller particles dominate the size distribution during the pre-transition and transition periods. In contrast, the summer period is mainly monomodal with only $20 \%$ opentype size distributions. The latter are most likely related to the high near-surface variabilities characterising the vertical profiles, cf. Figs. $3 \mathrm{~d}$ and e. The integrated BL size distributions for the three periods show a slight temporal decrease, cf. Table 2 . The values of $N_{10}$ together with these numbers suggest that during the campaign, around $40 \%$ of the particles were smaller than $20 \mathrm{~nm}$.

To summarise these results it may be stated that the largest variations of the distributions pertain to the smallest size-bins and occur during the pre-transition and transition periods both in the BL and in the FT. In the course of the campaign conditions in the FT undergoes a transition from a distribution dominated by Aitken-mode particles to one predominantly monomodal $(\sim 100 \mathrm{~nm})$. This non-stationarity of the FT is also underlined by the observed shift in variability, which decreases from the pre-transition period to the summer period.

\subsection{Mixing state of the aerosols}

To obtain more information about the chemical properties of the aerosols we investigate the external mixing of the population by heating the aerosols to a temperature of $250{ }^{\circ} \mathrm{C}$. By taking the ratio between the residual- and the total-particle numbers, the fraction of non-volatile particles is obtained, with the value 1 signifying that there are no volatile aerosols in the population. Note that we cannot tell if a particle has evaporated completely, but it will be considered as volatile if the remaining core is smaller than $6 \mathrm{~nm}$, which corresponds to a reduction in volume of $97 \%$ for a $20 \mathrm{~nm}$-particle (and even bigger reductions for larger-size particles).
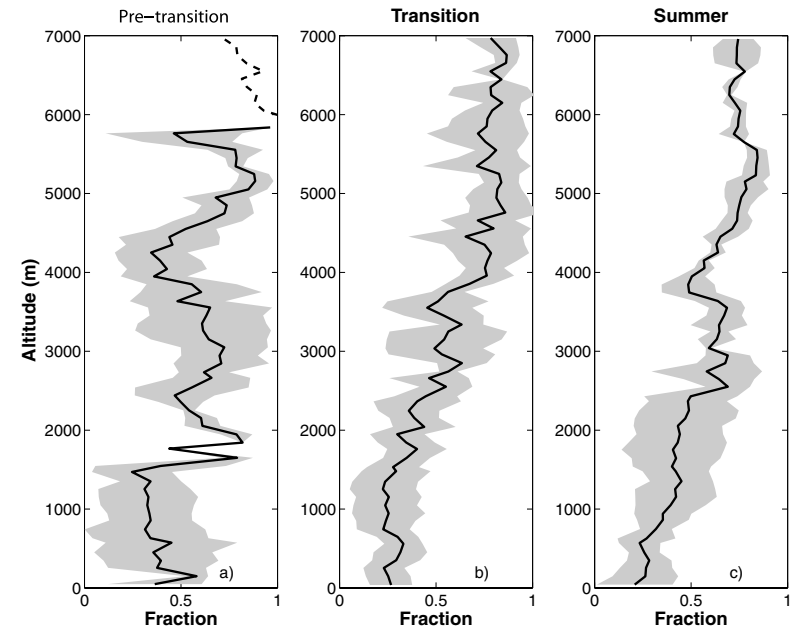

Fig. 5. Vertical profiles of the mean and standard deviation (shaded areas) of the fraction of non-volatile aerosols in the population of particles larger than $13 \mathrm{~nm}\left(N_{13}\right)$ during the pre-transition (a), transition (b) and summer (c) periods. (All data corrected for STP.)

The data sets available for the investigation were from 4 of 6,7 of 7 , and 5 of 6 flights for the three periods. Furthermore the amount of data within each vertical profile is limited due to clouds; the pre-transition period only had one data profile above $6 \mathrm{~km}$, the transition period three above $3.5 \mathrm{~km}$, and the summer period two above $5 \mathrm{~km}$.

To compare the three periods we graph the vertical profiles of the non-volatile fractions of $\mathrm{N}_{13}$ particle concentrations, cf. Figs. 5a-c. When investigating all flights within each period, two interesting features emerged; the fraction of non-volatile aerosols increases with altitude, whereas the BL as well as FT variability decreases as the campaign proceeds, except in a layer between 1 and $2.5 \mathrm{~km}$ that shows a larger variability during summer compared to the two preceding periods.

The transition and summer periods show roughly similar mean fractions of non-volatile aerosol concentrations. We note that this mean fraction decreases with height, from being around 0.5 in the lowest $100 \mathrm{~m}$ to having a minimum of around 0.3 at an altitude of $1.5 \mathrm{~km}$.

The large variability during the pre-transition period is due to the spread between the individual flight results. During the surveys performed on day 140 (when the $\mathrm{N}_{260}$ data show enhanced concentrations, cf. Fig. 1a) the anomalously high fraction of nonvolatile aerosols affects the mean value and the variability of the entire tropospheric column, cf. Fig. 5a. During the transition period the variability is seen to be smaller in the lower (below $3 \mathrm{~km}$ ) part of the troposphere, compared to summer. The data discrepancies between 1 and $2.5 \mathrm{~km}$ during the summer period arise from one flight showing a mean fraction between 0.1 and 0.4 , whereas the remaining five flights had a fraction ranging from 0.4 to 0.6 for the same altitude range, cf. Fig. 5c. Above 
$3 \mathrm{~km}$ the transition period is distinguished by a larger variability compared to the summer period (data based on three and two flights, respectively).

The lowest part of the BL, from the surface up to around $600 \mathrm{~m}$, shows a fraction of non-volatile aerosol concentration which decreases by a factor of two from the pre-transition period to the summer period. This pronounced decrease may be caused by the loading of anthropogenic material into the Arctic during day 140, which exerted a substantial influence on the average result from the pre-transition period (cf. Fig. 1a).

To investigate the size-dependence of the mixing state we used the 'heated' $\left(250{ }^{\circ} \mathrm{C}\right)$ data from the V-DMPS system and assembled figures showing the mean fraction and the standard deviation of non-volatile particle concentration as a function of size $(20-250 \mathrm{~nm})$. The BL results and the two sets of FT results (FT1 from the top of the BL to $3 \mathrm{~km}$; FT2 from 3 to $7 \mathrm{~km}$ ) are shown in Figs 6a-c and d-f, respectively. Note that the data available for these calculations originate from the same flights, as do the results presented in Fig. 4, that is, the summer period data are less representative than those from the pre-transition and transition periods.

From these diagrams it is recognized that the shapes of the distributions are generally similar for all three-altitude ranges during the whole campaign, that is, a small fraction (0.1-0.2) of non-volatile aerosol concentration over the smallest size range $(20-30 \mathrm{~nm})$ with an increasing fraction up to particle size $50 \mathrm{~nm}$.

The transition period shows a bimodal distribution with modes at 50 and $190 \mathrm{~nm}$ in the BL and at 70 and $200 \mathrm{~nm}$ in FT1 (in FT2 the second mode is difficult to quantify since the distribution ends at $250 \mathrm{~nm}$ ). The same bimodal structure is found in FT1 during the summer period, with modes at around 50 and $190 \mathrm{~nm}$. During the pre-transition and transition periods the FT1 and FT2 distributions more-or-less coincide with each other, and the same holds true for the variabilities. During the transition period bimodal distributions are found in both the BL and FT2, which is also the case for the FT1 and FT2 results in summer. In the BL the mean fraction of non-volatile particle concentration decreases during the campaign and the variability shows larger fluctuations during summer compared to the preceding periods, which is consistent with the integrated results in Fig. 5.

Our results concerning the non-volatile fractions of the aerosol populations may be summarised by noting that there are clear temporal and spatial differences between the three periods as regards the magnitude as well as the variability of the non-volatile fraction of the particles.

An interesting overall feature of the results in Figs. 6a-f is that the summer period differs significantly from the pre-transition and transition periods in that the average fraction of non-volatile aerosol concentration is considerably smaller in summer than during the preceding periods. The whole column shows an overall temporal decrease of the non-volatile fraction over the particle size range under consideration. The decrease is somewhat larger for the upper tropospheric layer (FT2) compared to the lower (FT1); the transition period clearly manifests this change between the two altitude ranges. We note that the integrated results presented in Fig. 5 did not show this trend as clearly as the size-resolved data did.
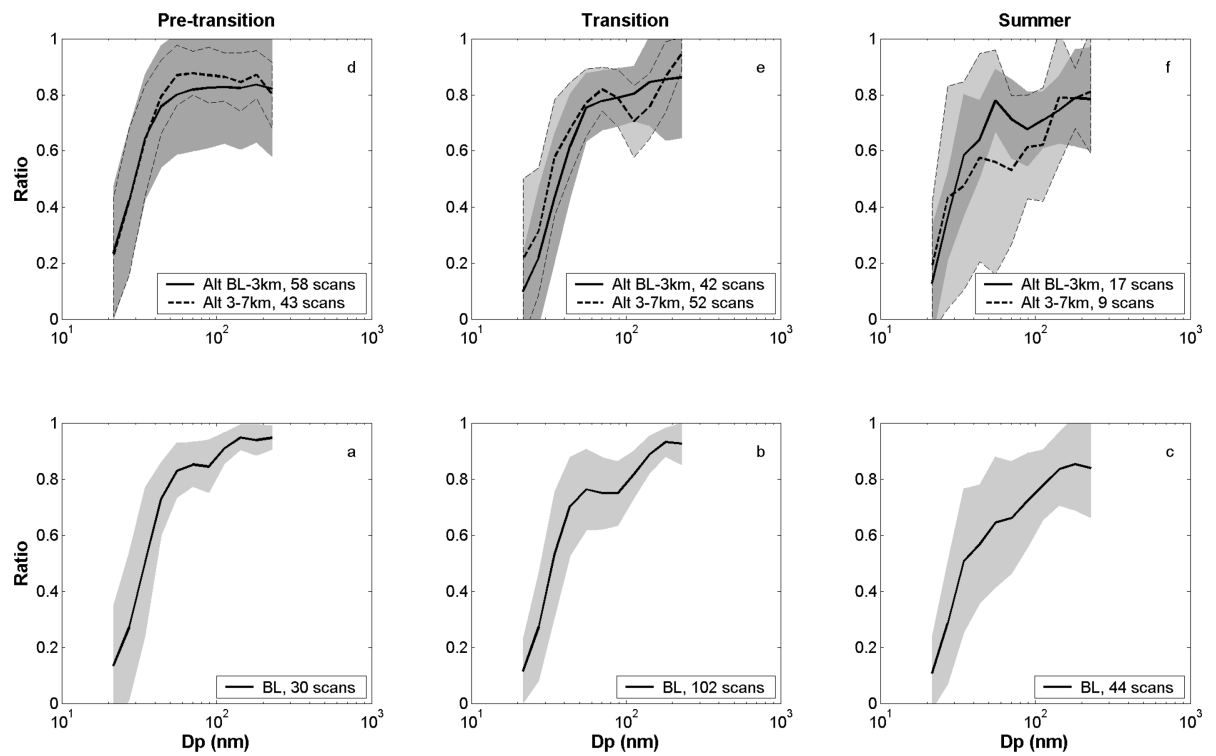

Fig. 6. Means (thick solid and dashed lines) and standard deviations (shaded areas) for the non-volatile size distribution measured with the V-DMPS system, range from 20 to $250 \mathrm{~nm}$. The panels from left to right show the pre-transition, transition, and summer periods. The BL results are shown in panels $(\mathrm{a}-\mathrm{c}$ ). The FT results (panels d-f) are composed of two groups: FT1 from the top of the BL to $3 \mathrm{~km}$ (thick solid lines and dark shaded areas) and FT2 from 3 to $7 \mathrm{~km}$ (thick dashed lines and light shaded areas). (All data corrected for STP.) 


\section{Discussion}

For a more comprehensive understanding of the results reported above, these must be interpreted within a wider framework incorporating the larger-scale transports affecting the Arctic region. Hence some results concerning the estimated ages of the Arctic air masses encountered during ASTAR 2004 will be presented here.

Based on the FLEXPART transport analyses it was found that during the pre-transition period the air masses affecting the experimental region moved across Siberia and at the end of this phase were found in northern Scandinavia. Throughout the subsequent transition period this shift continued, with the source region moving gradually towards the Atlantic Ocean and Greenland. During summer the air masses affecting Svalbard were found to have northwesterly and northerly origins within the Arctic.

Using the FLEXPART CO PSCs (cf. Section 2), we calculated $\mathrm{CO}$ age along each flight path, that is, the contribution for each of the $20 \mathrm{~d}$ of $\mathrm{CO}$ at the receptor in relation to the total concentration, hereby giving us an estimate of the transport time of the air mass from a potential source region. After averaging all the data over 100-m layers as in Figs. 3 and 5, the results summarized in Figs. $7 \mathrm{a}-\mathrm{c}$ were obtained.

Here it is seen that in the lower part of the troposphere, 0 $3000 \mathrm{~m}$, the mean age increases from being around $11 \mathrm{~d}$ during the pre-transition period to approximately $18 \mathrm{~d}$ in summer, whereas the variability decreases. The upper parts of the profiles, 3000-7000 m, show a more-or-less unchanged mean age of around $17 \mathrm{~d}$ during the entire campaign, while the associated
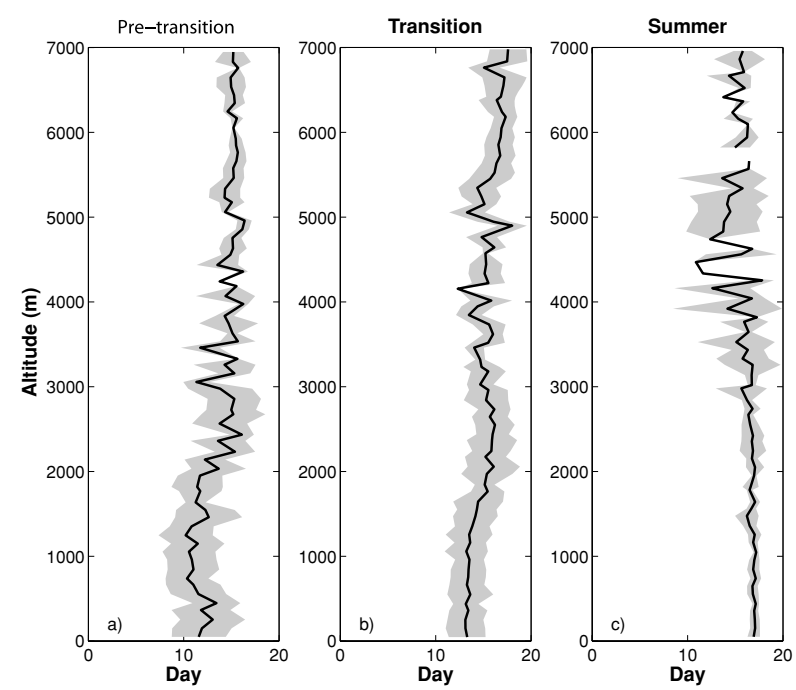

Fig. 7. Vertical profiles of the mean ages and standard deviations of the air masses for each period; (a) The pre-transition period (day 139-145), (b) the transition period (day 147-152) and (c) the summer period (153-158). The mean ages are averaged over 100-m layers through the entire tropospheric column from 0 to $7000 \mathrm{~m}$. variability increases. These results show that the FT air masses probably are affected by transport from distant areas, whereas the BL air masses having shorter residence times, except during the summer period when no striking differences between the FT and BL result are apparent.

The overall results of the present investigation support previous studies indicating that the Arctic FT is constituted by aged air masses (Yum and Hudson, 2001; Williams et al., 2002; Wylie and Hudson, 2002). This conclusion is given added weight by the results reported in Section 3 above, in particular those concerning the aerosol concentrations and the mixing state of the particle population. The aged Arctic air mass and the dearth of clouds in the FT make it possible for aerosols to grow without being washed out, and consequently they become more and more internally mixed. Hence the prominent feature of Fig. 5 that the fraction of non-volatile aerosols increases with altitude is consistent with the high-altitude air masses being aged. Furthermore, these air masses stood a reasonable chance of being influenced by more remote sources outside the Arctic, in agreement with the results summarised in Fig. 7.

The results in Figs. $3 \mathrm{~b}, \mathrm{~d}$ and $\mathrm{f}$ show enhanced $N_{260}$ concentrations, and furthermore a dominating monomodal size distribution $(\sim 100 \mathrm{~nm})$ is visible in Figs. $4 \mathrm{f}$ and i, indicating an old air mass in the absence of clouds. Note that also these results are consistent with the conclusion of the references quoted above.

During spring and summer, the Arctic troposphere is characterized by a low-altitude cloud cover as well as thin cirrus clouds in the upper troposphere. Since the latter remove fewer nuclei than the lower tropospheric clouds do, this results in a profile with few cloud condensation nuclei $(\mathrm{CCN})$ in the lower troposphere and high concentrations near the tropopause. The $\mathrm{BL}$ is often topped by clouds which scavenge larger particles, a process that give rise to differences in the $N_{260}$ variability between the BL and FT. This feature is in clear evidence from Fig. 3f, cf. the conditions at an altitude of $2 \mathrm{~km}$. The ageing process in the Arctic FT has been shown to have considerable implications for the formation of clouds. Based on airborne measurements in the Arctic troposphere during May 1998, Yum and Hudson (2001) as well as Wylie and Hudson (2002) showed that the concentrations of CCN increased with altitude over the Arctic Ocean. It was conjectured that the low percentage of liquid-phase clouds in the upper troposphere and the limited vertical mixing in the Arctic permit these increased CCN concentrations here.

The bimodal structures found in the size distributions of the mixing states (Figs. 6b,e and f) serve as an indication that the aerosol distribution results from a combination of different air masses. It has previously been shown (Jaeschke et al., 1997; Scheuer et al., 2003; Weber et al., 2003) that the transport of polluted air into the Arctic troposphere takes place in layers, which are from tens to hundreds of metres thick and have a horizontal extent of up to hundreds of kilometres. These can easily be distinguished from aircraft-measurement data in the form of the bimodal distributions seen in the abovementioned 
figures as well in the vertical profiles showing a layered structure of enhanced particle concentrations.

This layered structure is also found in the vertical particlenumber profiles obtained during the campaign, and, as seen in Figs. $3 \mathrm{a}-\mathrm{f}$, the one representing $N_{260}$ being somewhat less pronounced during summer than during the pre-transition period. A layered structure of $\mathrm{SO}_{2}$-polluted air masses has been reported from previous airborne studies in the Arctic during spring and summer, see for example, Jaeschke et al. (1997).

The vertical profiles of the $N_{10}$ concentrations in the boundary layer indicate that from the pre-transition to the summer period their geometric means decreased from 529 to $328 \mathrm{~cm}^{-3}$ and the variabilities from $273-1024$ to $132-861$. These overall values pertaining to the entire boundary-layer column are somewhat inappropriate for the picture that emerges when single vertical profiles are examined. These tend to show that the maximum as well as minimum particle concentrations occurred during summer and in thin $(\sim 100 \mathrm{~m})$ layers, which are not adequately represented when averaging over the entire boundary layer or free tropospheric column. The fact that this feature is found in the lower part of the troposphere (where cloud processes reduce the accumulation-mode-particle surface area available as a sink for precursor gases) is associated with the competition between sinks and sources of precursor gases when new particles are being formed, cf. Engvall et al. (2008).

Around $50 \%$ of the FT size distributions reported in Section 3 are dominated by the Aitken mode $(\sim 50 \mathrm{~nm})$; this is in full agreement with the results due to Garrett et al. (2002), who found high Aitken-nuclei concentrations above cloud tops in the Arctic spring. The present study shows, however, a dominance of accumulation-mode particles in the FT during summer (Figs. 4f and i) and that these consist of a larger fraction of condensable material than those during the pre-transition and transition periods, cf. Figs. 6a-c. (We note that the integrated results presented in Fig. 5 did not show this trend as clearly as did the size-resolved data.) This is in agreement with the results obtained during previous airborne studies in the FT, which showed that most photochemically-produced gas-phase species condensed onto pre-existing aerosols (Scheuer et al., 2003; Weber et al., 2003).

Remote sensing (Treffeisen et al., 2005) shows an upper-FT change in aerosol extinction/colour ratios from spring to summer, indicating an aerosol transition. These authors further suggest that the seasonal changes observed in long-term ground-based measurements (Herber et al., 2002; Ström et al., 2003) are not limited to the boundary layer, but take place in the whole vertical tropospheric column, a result which is confirmed by this study based on airborne observations.

\section{Summary and conclusions}

In-situ aerosol data collected in the Arctic troposphere during a three-week period (day 139-158) 2004 were analysed. The mea- surements took place at the time of the year when the characteristics of the aerosol distribution change from being accumulationmode dominated to being primarily of the Aitken-mode type, a process that has previously been observed in the boundary layer. To address the question whether this transition is also detectable in the FT, an aircraft-measured data set from the ASTAR 2004 campaign was analysed. Based on these results the following conclusions deserve to be highlighted:

(1) The measurements show that the transition takes place in the entire tropospheric column, with, however, different characteristics in the BL and in the FT: In the BL the concentration of smaller particles $\left(N_{10}\right)$ shows an increase of variability from the pre-transition phase to the transition and summer periods, whereas the $N_{260}$ concentration as well as variability remain stable over time. Above the BL, on the other hand, these latter particles show enhanced concentrations and variabilities during the entire campaign, with decreasing magnitudes and variability spans towards summer.

(2) Alterations of the vertical $\mathrm{N}_{10}$ distribution during the campaign indicated that the tropospheric column underwent a change; the concentrations were more-or-less evenly distributed over all altitudes during the pre-transition period, but subsequently showed a more layered structure.

(3) The 'open'-size distributions characterising the FT during the pre-transition and transition periods are followed by a monomodal distribution (100 nm) during summer. Results from the volatile-particle size distributions additionally indicate a larger fraction of vaporisable material during the summer period compared to the pre-transition and transition phases.

(4) The non-volatile fraction of the total-number concentrations increases with altitude, which indicates an aged aerosol in the upper part of the troposphere. This is probably due to cloud processes controlling the aerosol characteristics in the lower part of the troposphere, whereas the absence of clouds at higher levels gives rise to longer residence times of the aerosols in this zone.

(5) The results from transport analyses indicate that the age of the air masses below $3 \mathrm{~km}$ increased towards summer, from around $11 \mathrm{~d}$ initially to $17 \mathrm{~d}$ at the end of the campaign. Above 3 $\mathrm{km}$ the mean age of the air masses remains similar for all three periods, viz. 16-18 d.

(6) The airborne measurements from the boundary layer demonstrated that the temporal evolution of the aerosol properties is captured by the continuous measurements undertaken at the Zeppelin station, despite the intermittent character of the aerial surveys (on average three flights in $4 \mathrm{~d}$ ).

\section{Acknowledgments}

The authors thank Prof. Peter Lundberg at MISU for useful discussions and suggestions. Thanks also due to Birgitta Noone and Juri Waher for providing data from the Zeppelin station. They also acknowledge Swedish Environmental Protection Agency for supporting this work as part of the Environment Monitoring 
Program. Thanks to ITM, NIPR, AWI and pilots of the POLAR 4 air craft. A. S. was supported by the Norwegian Research Council in the framework of POLARCAT. The DLR contribution to ASTAR 2004 was partly supported by the Deutsche Forschungsgemeinschaft (DLR) under reference number MI 583/3-3.

\section{References}

Baumgardner, D., Dye, J. E., Gandrud, B. W. and Knollenberg, R. G. 1992. Interpretation of measurements made by the forward scattering spectrometer probe (Fssp-300) during the airborne Arctic stratospheric expedition. J. Geophys. Res.-Atmos. 97, 8035-8046.

Bodhaine, B. A. 1989. Barrow surface aerosol - 1976-1986. Atmos. Environ. 23, 2357-2369.

Bodhaine, B. A., Harris, J. M. and Herbert, G. A. 1981. Aerosol lightscattering and condensation nuclei measurements at Barrow, Alaska. Atmos. Environ. 15, 1375-1389.

Engvall, A.-C., Krejci, R., Ström, J., Treffeisen, R., Scheele, R. and coauthors 2008. Changes in aerosol properties during spring-summer period in the Arctic troposhere. Atmos. Chem. Phys., 8, 1-18.

Garbrecht, T., Herber, A., Steinhage, D. and Zielinski, O., 2006. Sensor network for polar research aircraft. Environ. Res. Arctic, 127-133.

Garrett, T. J., Hobbs, P. V. and Radke, L. F. 2002. High Aitken Nucleus Concentrations above Cloud Tops in the Arctic. J. Atmos. Sci., 59, 779-783.

Herber, A., Thomason, L. W., Gernandt, H., Leiterer, U., Nagel, D. and co-authors 2002. Continuous day and night aerosol optical depth observations in the Arctic between 1991 and 1999. J. Geophys. Res.Atmos. 107, doi:10.29/2001JD000536.

Jaeschke, W., Beltz, N., Dierssen, J. P., Haunold, W., Krischke, U. and co-authors 1997. Measurements on the distribution of trace substances in the Arctic troposphere. Atmos. Res. 44, 199-221.

Jokinen, V. and Makela, J. M. 1997. Closed-loop arrangement with critical orifice for DMA sheath excess flow system. J. Aerosol. Sci. 28, 643-648.

Knutson, E. O. and Whitby, K. T. 1975. Aerosol classification by electric mobility: apparatus, theory and applications. J. Aerosol Sci. 6, 443451.

Olivier, J. G. J. and Berdowski, J. J. M. 2001. Global emissions sources and sinks, in The Climate system (edsJ. Berdowski, R. Guicherit, and B. J. Heij), A. A. Balkema, Brookfield, Vt, 33-78.

Quinn, P. K., Miller, T. L., Bates, T. S., Ogren, J. A., Andrews, E. and co-authors 2002. A 3-year record of simultaneously measured aerosol chemical and optical properties at Barrow, Alaska. J. Geophys. Res.Atmos. 107, doi:10.1029/2001JD001248.

Quinn, P. K., Shaw, G., Andrews, E., Dutton, E. G., Ruoho-Airola, T. and co-authors 2007. Arctic haze: current trends and knowledge gaps. Tellus B 59, 99-114.

Rinke, A., Dethloff, K., Spekat, A., Enke, W. and Christensen, J. H. 1999. High resolution climate simulations over the Arctic. Polar Res. 18, 143-150.

Scheuer, E., Talbot, R. W., Dibb, J. E., Seid, G. K., DeBell, L. and coauthors 2003. Seasonal distributions of fine aerosol sulfate in the North
American Arctic basin during TOPSE. J. Geophys. Res.-Atmos. 108, doi:1029/2001JD001364.

Schröder, F. and Ström, J. 1997. Aircraft measurements of sub micrometer aerosol particles $(>7 \mathrm{~nm})$ in the midlatitude free troposphere and tropopause region. Atmos. Res. 44, 333-356.

Shiobara, M., Yabuki, M. and Kobayashi, H. 2003. A polar cloud analysis based on micro-pulse Lidar measurements at Ny-Alesund, Svalbard and Syowa, Antarctica. Phys. Chem. Earth. 28, 1205-1212.

Sirois, A. and Barrie, L. A. 1999. Arctic lower tropospheric aerosol trends and composition at Alert, Canada: 1980-1995. J. Geophys. Res.-Atmos. 104, 11599-11618.

Stein C., Shröder F., and Petzold A. 2001. The condensation Particle size Analyzer: a new instrument for the measurement of ultrafine aerosol size distributions, Abstracts of the European Aerosol Conferenc 2001. J. Aerosol Sci., 32, 381-382.

Stohl, A. and Thomson, D. J. 1999. A density correction for Lagrangian particle dispersion models. Bound-Lay Meteorol. 90, 155-167.

Stohl, A., Forster, C., Frank, A., Seibert, P. and Wotawa, G. 2005. Technical note: the Lagrangian particle dispersion model FLEXPART version 6.2. Atmos. Chem. Phys. 5, 2461-2474.

Ström, J., Umegård, J., Torseth, K., Tunved, P., Hansson, H. C. and co-authors 2003. One year of particle size distribution and aerosol chemical composition measurements at the Zeppelin Station, Svalbard, March 2000-March 2001. Phys. Chem. Earth. 28, 1181-1190.

Tjernström, M., Leck, C., Persson, P. O. G., Jensen, M. L., Oncley, S. P. and co-authors 2004. The summertime Arctic atmospheremeteorological measurements during the Arctic Ocean experiment 2001. B Am. Meteorol. Soc. 85, 1305-1321.

Treffeisen, R., Rinke, A., Fortmann, M., Dethloff, K., Herber, A. and coauthors 2005. A case study of the radiative effects of Arctic aerosols in March 2000. Atmos. Environ. 39, 899-911.

Treffeisen, R. E., Thomason, L. W., Ström, J., Herber, A. B., Burton, S. P. and co-authors 2006. Stratospheric aerosol and gas experiment (SAGE) II and III aerosol extinction measurements in the Arctic middle and upper troposphere. J. Geophys. Res.-Atmos. 111, doi:10.1029/2005JD006271.

Weber, R. J., Orsini, D., Wang, B., Scheuer, E., Talbot, R. W. and co-authors 2003. Investigations into free tropospheric new particle formation in the central Canadian arctic during the winter/spring transition as part of TOPSE. J. Geophys. Res.-Atmos. 108, doi:10.1029/2002JD002239.

Wiedensohler, A. 1988. An approximation of the bipolar chargedistribution for particles in the sub-micron size range. J. Aerosol. Sci. 19, 387-389.

Williams, J., de Reus, M., Krejci, R., Fischer, H. and Strom, J. 2002. Application of the variability-size relationship to atmospheric aerosol studies: estimating aerosol lifetimes and ages. Atmos. Chem. Phys. 2, 133-145.

Wylie, D. P. and Hudson, J. G. 2002. Effects of long-range transport and clouds on cloud condensation nuclei in the springtime Arctic. $J$. Geophys. Res.-Atmos. 107, doi:10.1029/2001JD000759.

Yum, S. S. and Hudson, J. G. 2001. Vertical distributions of cloud condensation nuclei spectra over the springtime Arctic Ocean. J. Geophys. Res.-Atmos. 106, 15045-15052. 